\title{
Multifocal Basal-Cell Carcinomas in a Nevus Sebaceus of Jadassohn
}

\author{
MORRIS WESTFRIED, M.D., AND GEORGE R. MIKHAIL, M.D.
}

\begin{abstract}
A lesion of nevus sebaceus with multifocal basal-cell carcinomas was excised by Mohs' fresh-tissue technique. Histologically, most of the foci of basal-cell carcinomatosis were of the superficial type, but the few more deeply situated foci had adamantinoid features. The malignancies extended well beyond the clinically discernible margins of the nevus sebaceus. Spontaneous healing of the wound of ablation resulted in a satisfactory appearance.
\end{abstract}

As EARLy AS 1908, Gavazzeni reported a basal-cell carcinoma complicating a nevus sebaceus. ${ }^{1}$ Since then, the incidence of basal-cell carcinomas developing in lesions of nevus sebaceus has been reported to be as high as $22 \% .^{2,3}$ The carcinomas are usually not aggressive and are easily managed. A case of nevus sebaceus is reported here in which several basal-cell carcinomas developed multifocally, most of superficial character in histology, some more deeply situated and adamantinoid in features, and altogether well beyond the clinically discernible margins of the nevus sebaceus.

\section{CASE REPORT}

A 61-year-old black woman sought attention because of ulceration and bleeding from a verrucous lesion that had been present on the right ear since birth. On examination, a hyperpigmented, verrucous plaque, measuring $2 \times 6 \mathrm{~cm}$, was found situated on the posterior aspect of the pinna of the right ear and adjacent postauricular sulcus. It extended from the superior rim of the pinna to the prominence of the mastoid and had an ulcerated area measuring $1.5 \mathrm{~cm}$ in diameter in the

Dr. Westfried is Chief of the Chemosurgery Clinic, Westchester Medical Center, and Assistant Clinical Professor of Dermatology, New York Medical College, Valhalla, New York.

Dr. Mikhail is Clinical Associate Professor of Dermatology, University of Michigan, and Director of the Chemosurgery Section of the Department of Dermatology, Henry Ford Hospital, Detroit, Michigan.

Address reprint requests to M. Westfried, M.D., Department of Dermatology, New York Medical College, Valhalla, NY 10595. center of the lesion (Fig. 1). A biopsy specimen showed hyperkeratosis, papillomatosis, numerous mature sebaceous glands in the upper dermis, and prominent apocrine glands in the lower dermis, features characteristic of nevus sebaceus and, in addition, solid masses of basaloid cetls with peripheral palisading embedded in a fibrovascular stroma. Most of the foci of

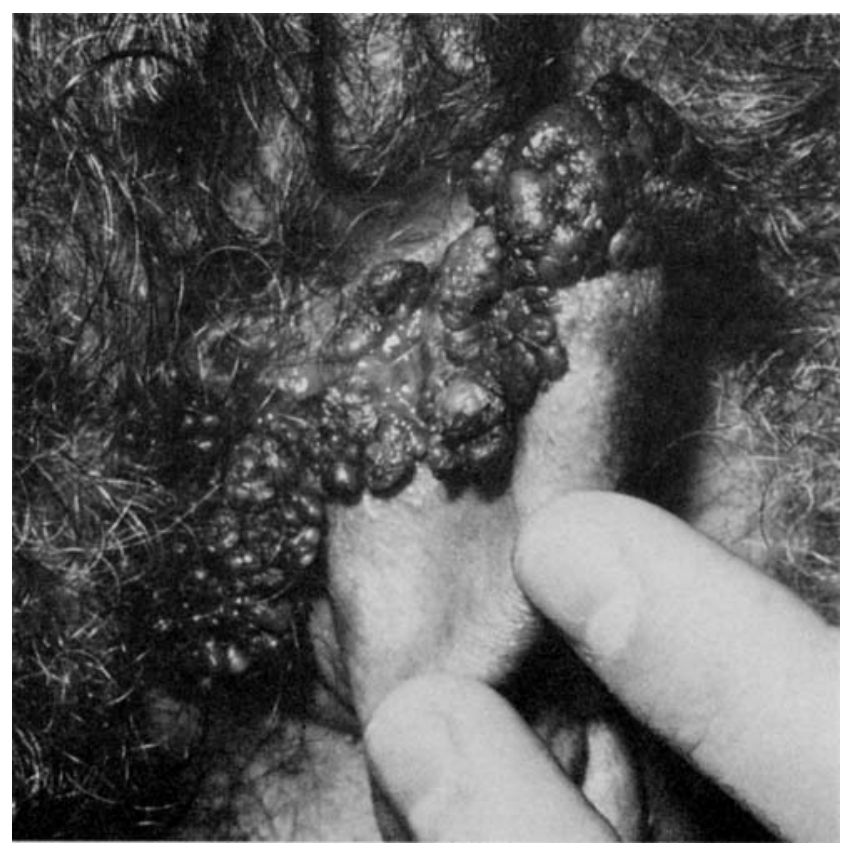

FIGURE 1. Clinical appearance of a hyperpigmented and verrucous nevus sebaceus complicated by carcinomatosis on the posterior aspect of an ear and on adjacent skin. 


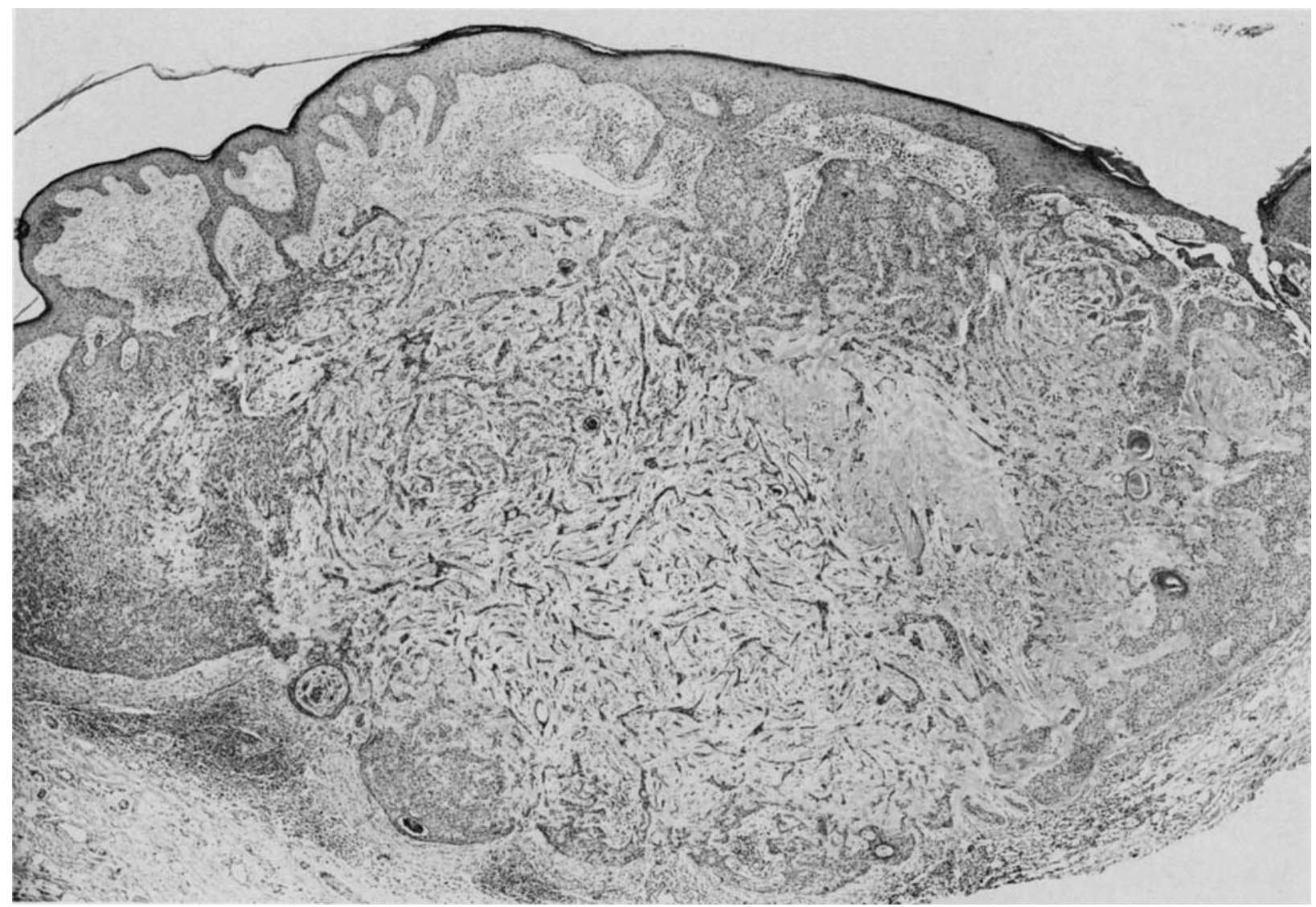

FIGURE 2. Histology of the carcinomatous development in the lesion pictured in Figure 1, showing adamantinoid basal-cell carcinoma. Note the edematous stroma, the stellate morphology of the neoplastic cells in the center, and the palisading on the left. (H\&E, original magnification $\times 32$ )

carcinomatosis were superficial; others extended deeper in the dermis and were composed of cells of stellate shape that contained elongated nuclei, a picture that is reminiscent of an adamantinoma (Fig. 2). The entire lesion was excised by the microscopically controlled fresh-tissue technique under local block anesthesia. Foci of superficial carcinomatosis that were clinically not suspected were found in the nevus sebaceus by the type of surgery practiced. The surgical wound measured $2.8 \times 6.8 \mathrm{~cm}$. The patient declined a graft upon the wound, which was consequently left to heal by secondary intention. Healing was complete within six weeks with a satisfactory cosmetic result (Fig. 3).

\section{COMMENT}

Basal-cell carcinomas and syringocystadenomata papillifera are the most common secondary neoplasms that may arise in sebaceous nevi. ${ }^{3}$ Squamous-cell car- cinomas and adnexal carcinomas occur less frequently. ${ }^{4}$ The association of nevus sebaceus with benign epithelial neoplasms, e.g., syringomata, apocrine cystadenomata, hidradenomata, and sebaceous epitheliomata, has also been observed, ${ }^{2,3}$ and combinations of neoplasms in a single lesion of nevus sebaceus are not rare. Mehregan and Pinkus, in a series of 150 cases, found 13 with several simultaneous secondary neoplasms. ${ }^{3}$ The simultaneous occurrence of superficial and deeply invasive basal-cell carcinomas has also been reported..$^{2,4}$

The deeply invasive basal-cell carcinoma in our case was of the adamantinoid type. This histologic variant has an appearance similar to dental ameloblastoma or adamantinoma. Adamantinomatous appearance is characterized by edematous stroma, peripheral palisading, and stellate cells that form a cribriform pattern. The stroma is replete with hyaluronic acid and chondroitin sulfate. ${ }^{5}$ The biologic behavior of this type 


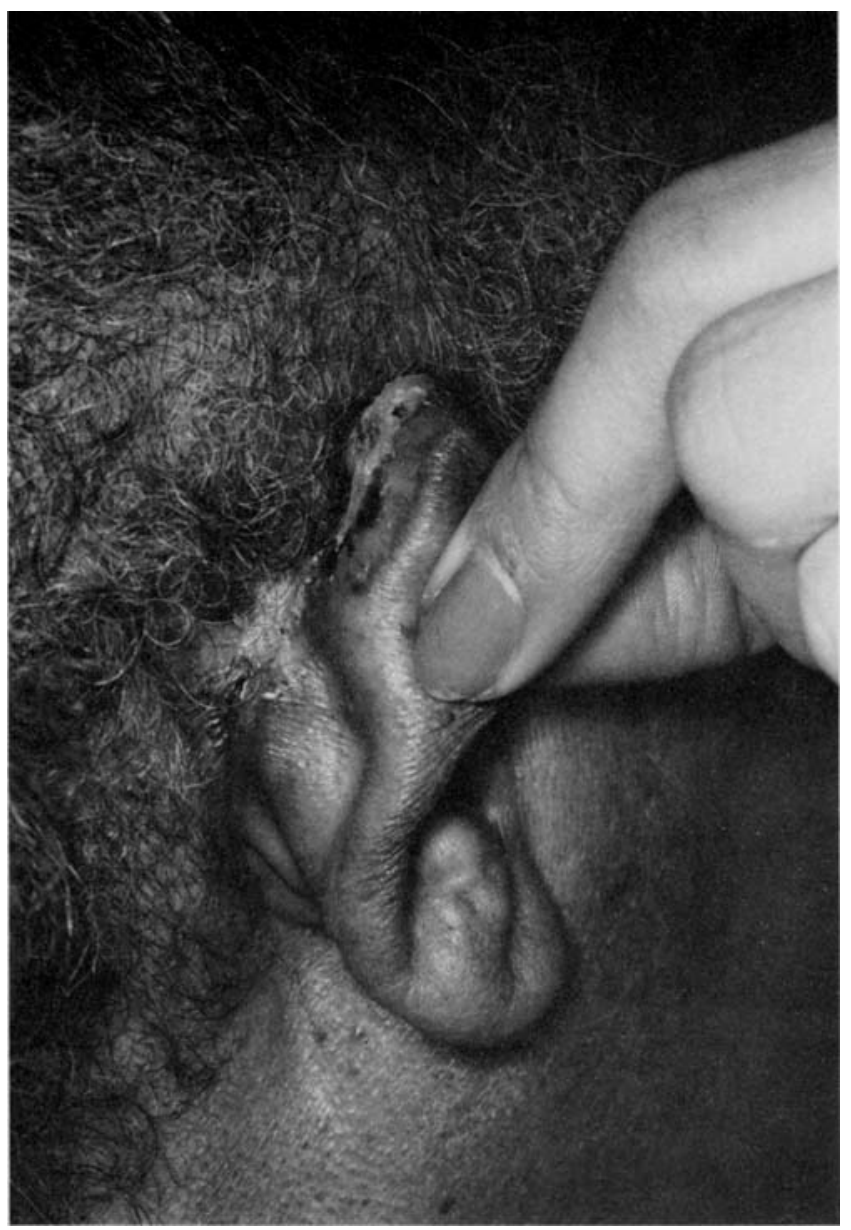

FIGURE 3. Clinical appearance of the site of the nevus sebaceus and its carcinomatous complication six weeks after excision and spontaneous healing.

of neoplasia does not differ from that of other forms of basal-cell carcinoma and, therefore, does not carry any special prognostic implications.

The need for prophylactic excision of nevus sebaceus and close follow-up has been stressed. ${ }^{6,7} \mathrm{Al}-$ though superficial destruction by curettage and electrodesiccation may be effective, we think that surgical excision is the treatment of choice. Mohs' techniques offer microscopic control of the excision of the preexisting nevus and secondary carcinomas therein. That method assures removal of neoplasia in areas that may not be clinically identifiable especially when the carcinomatosis develops in multiple foci. The satisfactory result by spontaneous healing of a large surface wound in this case is also worthy of note.

\section{REFERENCES}

1. Gavazzeni, C. A. Talgdrüsen-Hyperplasia und Epitheliom. Arch. Dermatol. Syphilol. 92:323-336, 1908.

2. Wilson Jones, E., and Heyl, T. Naevus sebaceus: A report of 140 cases with special regard to the development of secondary malignant tumors. Br. J. Dermatol. 82:99-117, 1970.

3. Mehregan, A. H., and Pinkus, H. Life history of organoid nevi. Arch. Dermatol. 91:574-588, 1965.

4. Domingo, J., and Helwig, E. B. Malignant neoplasms associated with nevus sebaceus of Jadassohn. J. Am. Acad. Dermatol. 1:545-556, 1979.

5. Lerchin, E., and Rahbari, H. Adamantinoid basal cell epithelioma. Arch. Dermatol. 111:586-588, 1979.

6. Lillis, P. J., and Ceilley, R. I. Multiple tumors arising in nevus sebaceus. Cutis 23:310-314, 1979.

7. Braitman, M. Supervention of a pigmented basal-cell carcinoma upon a nevus sebaceus. J. Dermatol. Surg. Oncol. 5:232-233, 1979. 